\title{
Balloon atrial septostomy under echocardiographic control: six years' experience and evaluation of the practicability of cannulation via the umbilical vein
}

\author{
M Ashfaq, A B Houston, J P Gnanapragasam, S Lilley, E P Murtagh
}

\begin{abstract}
Balloon atrial septostomy was undertaken under cross sectional echocardiographic control in 63 consecutive infants: in no case was fluoroscopic imaging required. The procedure was performed in the cardiac catheterisation laboratory, ward side room, or at the bedside in the neonatal intensive care unit. Catheterisation via the umbilical vein was attempted in 37 infants aged $<48$ hours old and was successful in 27. No complication was clearly attributable to the procedure though two infants died. A nine day old child died from disseminated intravascular coagulation the day after septostomy by the iliofemoral route and another, aged nine days, died of necrotising enterocolitis which had developed when he was eight days old, after umbilical catheterisation at eight hours.

Balloon atrial septostomy is a safe and easy procedure under cross sectional echocardiographic imaging control. Catheterisation via the umbilical vein was safe, easy to perform, and is appropriate in infants aged $<48$ hours.
\end{abstract}

Balloon atrial septostomy remains an important palliative procedure in many infants with cyanotic congenital cardiac conditions. ${ }^{1}$ After its introduction in $1966^{2}$ the procedure was performed under the control of fluoroscopic imaging. This form of imaging does not show the intracardiac structures directly and because the catheter has to be manipulated in relation to the anatomical landmarks on the image the risk of damage to the related intracardiac structures is increased. ${ }^{3}$ Recently it has become possible to perform septostomy under the imaging control of cross sectional echocardiography. ${ }^{4}$ This shows clearly the intracardiac anatomy and the precise position of the catheter tip, which reduces the risk of inadvertently damaging the mitral valve or other intracardiac structures. Not all workers accept ultrasound as the most appropriate imaging control for all patients. ${ }^{5}$

Catheterisation via the umbilical vein allows a catheter to be inserted easily and quickly into the heart but it does not permit much catheter manipulation. Because during balloon atrial septostomy the catheter requires only slight manipulation to enter the left atrium and because most infants undergoing septostomy do not need a formal catheter investigation the umbilical vein may provide a suitable route.

Earlier studies of cross sectional echocardiographic imaging in balloon atrial septostomy were small $^{4}$ or compared this technique with that of fluoroscopic imaging. ${ }^{6}$ We are not aware of any long term study of the routine use of echocardiographic imaging control for atrial septostomy or of the assessment of the use of the umbilical vein for catheterisation. For six years we have used the umbilical vein and echocardiographic imaging control for balloon atrial septostomy.

\section{Patients and methods}

Sixty three patients underwent balloon atria septostomy at the Royal Hospital for Sick Children, Glasgow, between September 1984 and September 1990. Initially septostomy was not routine in those with univentricular heart with absent right atrioventricular connection (tricuspid atresia) but this policy changed and more septostomies were carried out in the later period of the study. At the time of septostomy 18 patients were $<24$ hours old, 30 were $24-48$ hours old, and 15 were $>$ two days old. Birth weights ranged from 1.4 to 4.7 (mean 3.3 ) $\mathrm{kg}$.

We used the procedure to palliate various congenital cyanotic conditions: transposition of the great arteries (46), pulmonary atresia (seven), tricuspid atresia (seven), hypoplastic left heart syndrome (one), and other complex congenital cardiac anomalies (two) with or without transposition of great arteries. At the time of septostomy 34 patients were being treated with a prostaglandin infusion.

The underlying cardiac defect was diagnosed on cross sectional echocardiography, with the addition of colour Doppler flow mapping from January 1987. At first we used commercial ATL equipment (Advanced Technology Laboratories) and later a Vingmed CFM 700, both with a $5 \mathrm{MHz}$ transducer.

We catheterised the umbilical vein or iliofemoral vein with a 5F Fogarty atrial septostomy balloon catheter (Edwards laboratories). When we used the umbilical venous route we cleaned the stump and transected it near the skin. The catheter tip was inserted directly into the lumen of the umbilical vein and gently 
Figure 1 Modified subcostal view showing a clear image of the catheter with the umbilical vein as route of entry for the catheter. The catheter traverses the ductus venosus and enters the right atrium and left atrium through a patent foramen ovale. Parts of the left atrium, interatrial septum, and a pulmonary vein are also visible.

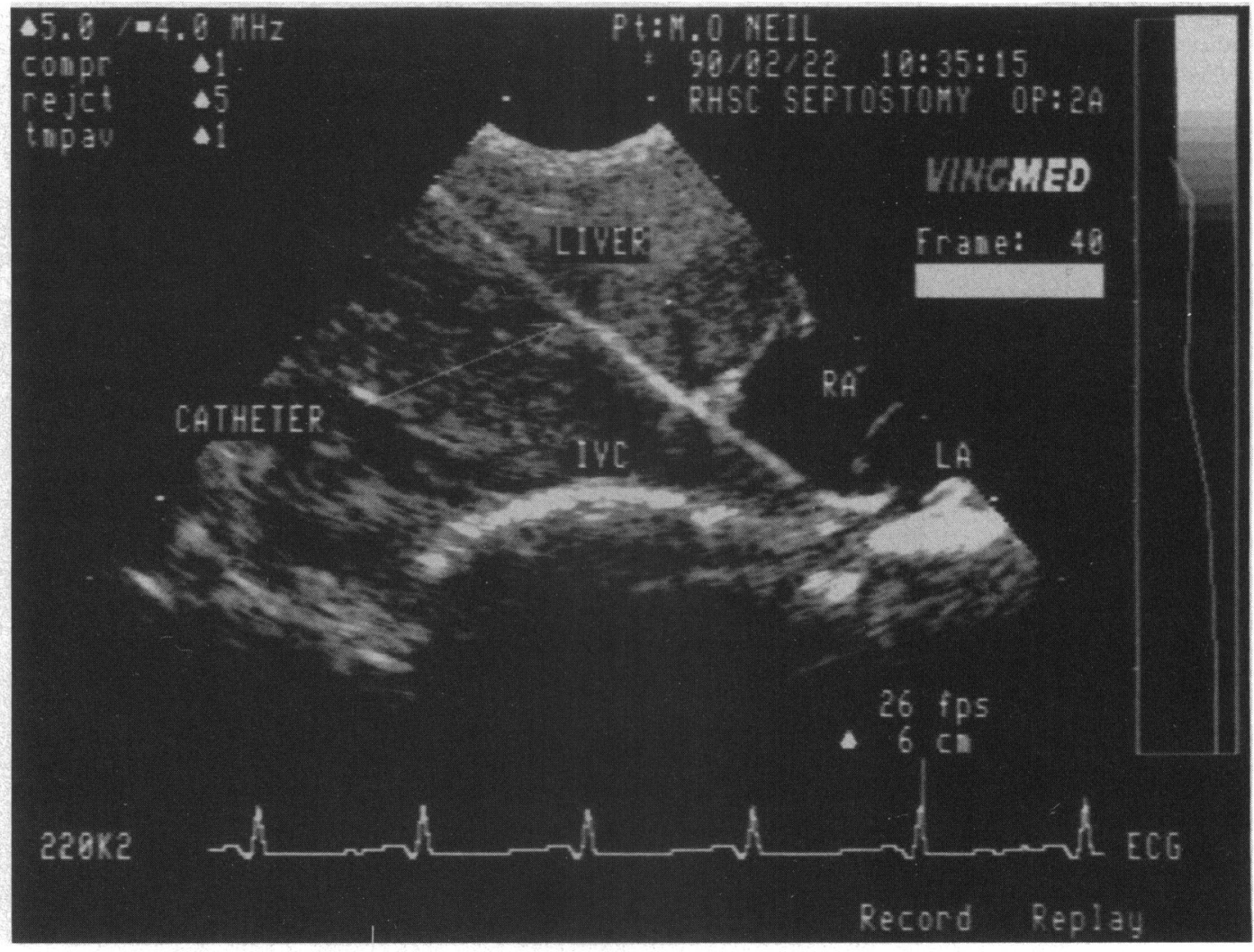

advanced and rotated if we encountered resistance. To get the catheter into the inferior vena cava we sometimes had to press gently on the subxiphoid region or use the central wire to straighten the tip of the catheter. We could see the catheter passing through the liver (fig 1) but the image was not of practical value when we had difficulty passing the catheter through the ductus venosus. If the catheter could not be passed easily into the heart the procedure was not prolonged and the femoral route was used.

At the end of the procedure the stump was sutured. No antibiotics were administered before or after the procedure. When the femoral route was used the catheter was introduced either percutaneously through a French gauge 7 sheath or, if this was unsuccessful, by cut down. We attempted to catheterise the umbilical vein in those infants who were less than 48 hours old; we succeeded in 27 and failed in 10. The iliofemoral route was used electively in 26 patients, 11 of whom were less

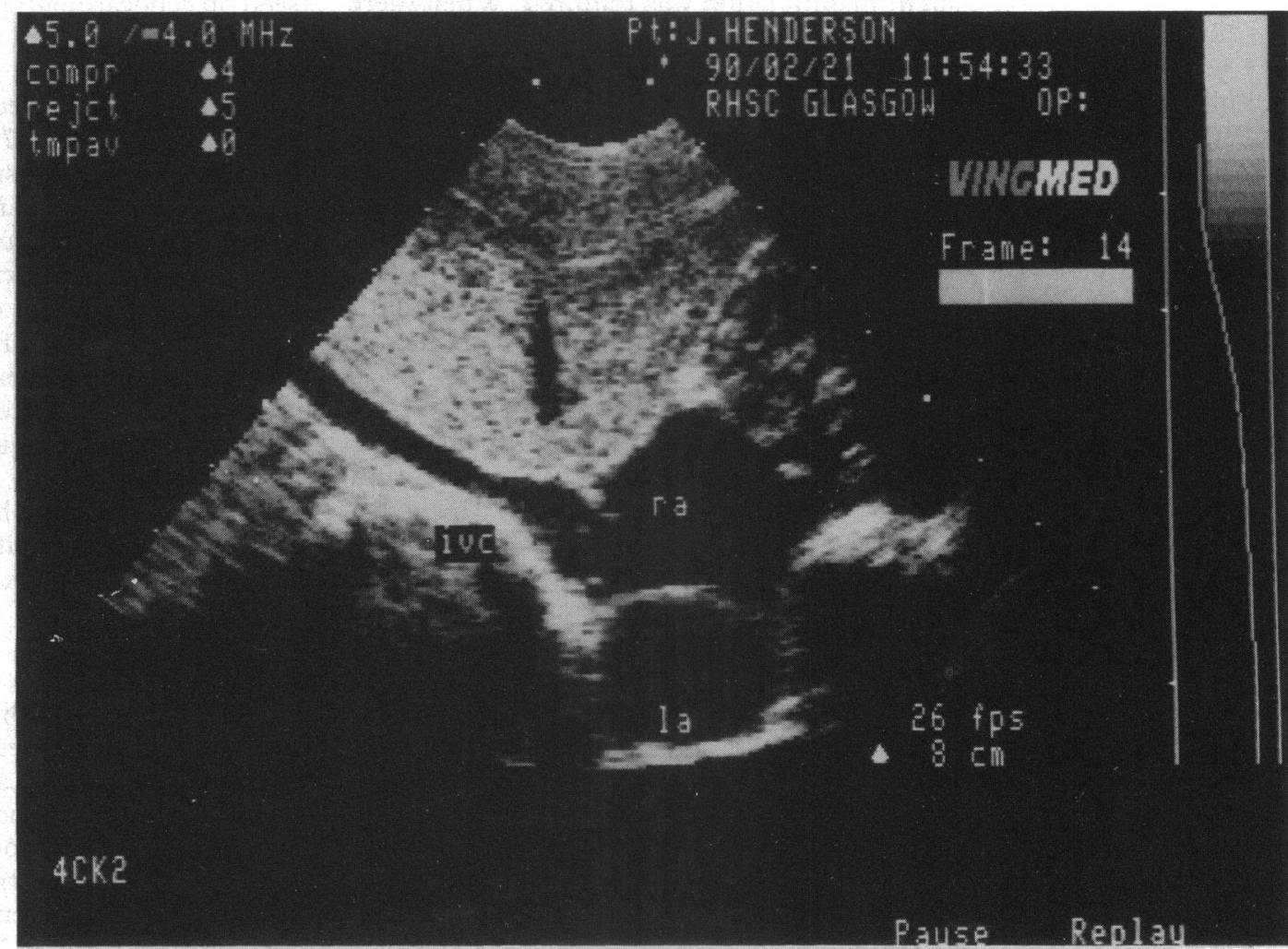

Figure 2 Subcostal four chamber view obtained by medial and superio angulation of the transducer showing the inferior vena cava (ivc), right atrium ( $\mathrm{ra}$ ), interatrial septum, and left atrium (la) in one plane. This view facilitated manipulation of balloon catheter. Both

atrioventricular valves and the interventricular septum can also be seen. 


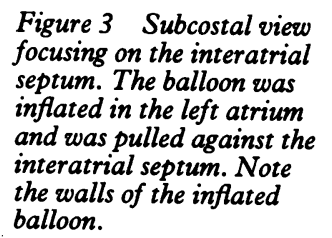

balloon.

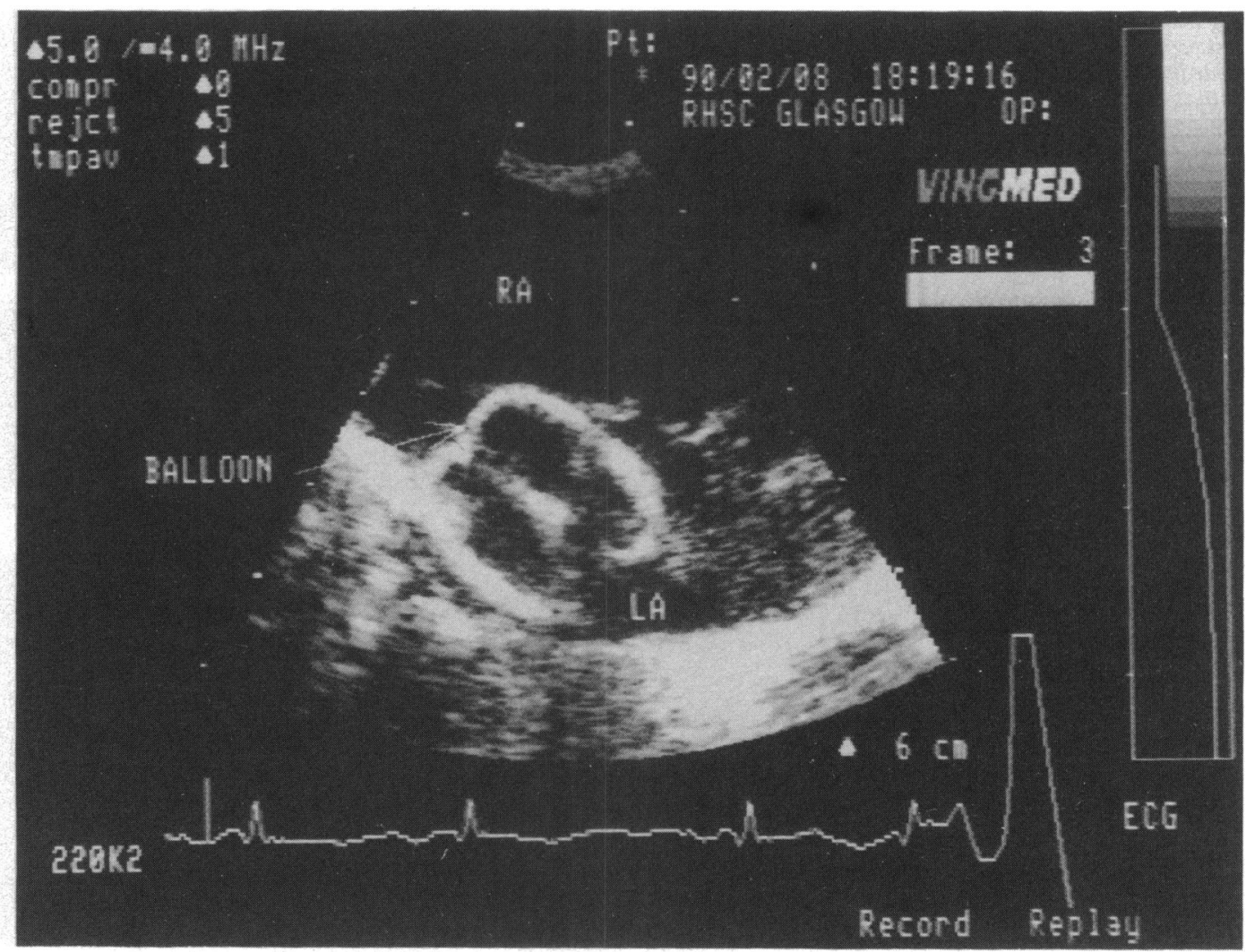

than two days of age. Four of these patients needed concomitant diagnostic cardiac catheterisation.

We inserted the balloon catheter using a subxiphoid four chamber view as a guiding image. In most infants the catheter passed easily from the right atrium through the patent foramen ovale into the left atrium and only slight manipulation was required. When there was difficulty we used an image obtained by medial angulation and rotation from a subcostal long axis view to guide the passage of the catheter tip through the fossa. This view shows the junction between the inferior vena cava and the right atrium, eustachian valve, atrial septum, and left atrium ${ }^{7}$ (fig 2). When the catheter tip was shown to be in the left atrium it was inflated with saline and gently pulled back until it apposed the atrial septum (fig 3) and then it was pulled through into the right atrium. It was inflated with 2-4 $\mathrm{ml}$ and pulled back several times until it became easy to pull the catheter through the septal hole and cross sectional and colour Doppler echocardiography showed a good sized hole.

We decided to use echocardiographic imaging for balloon atrial septostomy for 10 months when, because the catheterisation laboratory was being modernised, screening facilities in the hospital were not adequate. We performed the procedure in the ward side room, but later we returned to the catheterisation laboratory because nursing staff and ultrasound and other equipment used in the procedure were available. In addition, in two very ill neonates the procedure was performed in the neonatal intensive care unit.

\section{Results}

We used echocardiographic imaging control for septostomy in all patients, including the four who had diagnostic catheterisation. The images were adequate for the procedure in all; none needed fluoroscopy to guide the passage of the catheter through the septum. In all patients the size of the atrial septal defect we created (seen on echocardiographic image or by colour flow mapping) showed that the procedure was successful.

We only attempted to catheterise the umbilical vein in the 37 infants who were $<48$ hours old. We were unsuccessful in 10: three of the $18<24$ hours old and seven of the 19 aged between 24 and 48 hours of age. Catheterisation or attempted catheterisation of the umbilical vein did not cause any recognisable complications. Two infants died: the first had atrial septostomy by femoral cut down on the eighth day and died the next day of disseminated intravascular coagulation, while the other underwent septostomy through the umbilical vein when he was eight hours old and died from necrotising enterocolitis which developed

\section{Discussion}

Echocardiography rather than cardiac catheterisation is now used to investigate many aspects of congenital cardiac defects. Defects can be imaged by echocardiography and their severity and haemodynamic importance assessed by Doppler ultrasonography. In many cases surgical intervention can be reliably based on such studies. ${ }^{89}$ when he was eight days old. 
Interatrial balloon septostomy is a lifesaving palliative technique in patients with transposition of the great arteries and allied conditions. Previously the procedure was performed under fluoroscopic control with the balloon catheter being manipulated in relation to anatomical landmarks on the fluoroscopic image rather than actual visualisation of the interatrial septum and related intracardiac structures such as the atrioventricular valves. With this imaging technique there is the risk that balloon inflation will damage the atrioventricular valves if a balloon thought to be in the left atrium is really in a ventricle. ${ }^{3}$

The intracardiac anatomy is more clearly and precisely displayed when the procedure is undertaken under cross sectional echocardiographic imaging control. In addition, the defect created by the balloon can be seen and accurately measured, a procedure that is virtually impossible with catheterisation and angiography. This approach is helpful in patients in whom the position of the heart is abnormal and it is difficult to see the relative positions of the atrial septum and atrioventricular valves by $x$ ray screening. Our findings in this series of 63 patients who underwent balloon atrial septostomy over a period of six years showed that cross sectional echocardiographic imaging was a reliable guide for manipulation of the balloon catheter. Where there is any difficulty in passing the catheter through the atrial septum the modified subcostal view ${ }^{7}$ should be used.

We believe that when balloon atrial septostomy is performed under the control of cross sectional echocardiographic imaging the procedure is safer, less time consuming, and avoids exposing the patient and operator to radiation. With this imaging technique the procedure can also be performed at the bedside, in the intensive care unit, or other places where fluoroscopy is not available. It does need the cooperation of two trained operators, one to perform the procedure and the other to obtain the echocardiographic image. Because most centres that treat congenital heart defects now have a good echocardiographic service, it will not be difficult to perform such procedures under the control of ultrasound image.

Most infants requiring atrial septostomy are seen in the first two days of life when the ductus venosus is potentially patent and may be used to perform the septostomy. The technique is simple and quick and can be readily performed in cramped conditions such as in an incubator in an intensive care unit. It has also been stated that "this approach saves a vein". ${ }^{10}$ But we failed to pass the catheter in $25 \%$ of infants; so is it appropriate to use this approach first rather than the femoral one? Ten years ago the risk of venous thrombosis from percutaneous catheterisation was $16 \%$ in infants under six months. ${ }^{11}$ Though the real risk now is likely to be lower it cannot be disregarded. As far as we are aware no patient in our series developed such a complication, and in view of this and the small study groups we cannot be certain which approach has fewer complications. In view of the simplicity and safety of using the umbilical route our present policy in those under 48 hours initially is to clean both the umbilicus and the groin; if the catheter does not pass easily through the ductus venosus we then immediately attempt the percutaneous approach through the groin.

JPG is supported by a grant from the Equipment Evaluation Committee of the Scottish Home and Health Department.

1 Mok Q, Darvell F, Mattos S, et al. Survival after balloon atrial septostomy for complete transposition of great arteries. Arch Dis Child 1987;62:549-53.

2 Rashkind WJ, Miller WW. Creation of an atrial septal defect without thoracotomy. $J A M A$ 1966;196:991-2.

3 Venables AW. Balloon atrial septostomy in complete transposition of great arteries in infancy. Br Heart J 1970, position

4 Allan LD, Leanage R, Wainwright R, Joseph MC, Tynan $M$. Balloon atrial septostomy under two dimensional M. Balloon atrial septostomy under two dimens
echocardiographic control. Br Heart J 1982;47:41-3.

5 Benson L. Interventional cardiac catheterisation. Current Opinion in Cardiology 1990;5:40-4.

6 Lin AE, Di Sessa TG, Williams RG, Leighton J, Gross K Wong AL. Balloon and blade atrial septostomy facilitated by two-dimensional echocardiography. Am J Cardio 1986;57:273-7.

7 Lau KC, Mok CK, Lo RN, Leung MP, Yeung CY. Balloon atrial septostomy under two-dimensional echocardiographic control. Pediatr Cardiol 1987;8:35-7.

8 Huhta JC, Glasow P, Murphy DJ, et al. Surgery without catheterisation for congenital heart defects: managemen of 100 patients. J Am Coll Cardiol 1987;9:823-9.

9 D'Orsogna L, Sandor GGS, Patterson MWH, Ashmore PG, Le Blanc J, Culham JAG. Influence of echocardiography in pre-operative cardiac catheterisation in congenital heart disease. Int J Cardiol 1989;24:19-26.

10 Anderson RH, Macartney FJ, Shinebourne EA, Tynan M, eds. Cardiac catheterisation and angiocardiography. In: Paediatric cardiology Edinburgh, London, Melbourne, Paediatric cardiology Edinburgh, London, Melbo

11 Keane JF, Lang P, Newburger J, Fyler DC. Iliac veininferior caval thrombosis after cardiac catheterisation in infancy. Pediatr Cardiol 1980;1:257-61. 